\title{
A Reporter Transgene Indicates Renal-specific Induction of Tumor Necrosis Factor (TNF) by Shiga-like Toxin \\ Possible Involvement of TNF in Hemolytic Uremic Syndrome
}

\author{
Yaron Harel, * Maria Silva," Brett Giroir, * Arthur Weinberg, " Thomas B. Cleary," and Bruce Beutler" \\ Departments of ${ }^{*}$ Pediatrics, ${ }^{\ddagger}$ Pathology, and ${ }^{\S}$ Internal Medicine, and the Howard Hughes Medical Institute, The University of Texas \\ Southwestern Medical Center, Dallas, Texas 75235-9050; and "Department of Pediatrics, \\ University of Texas Medical School, Houston, Texas 77025
}

\begin{abstract}
We have examined the hypothesis that TNF may play a pathogenetically important role in the hemolytic uremic syndrome. Specifically, we considered the possibility that shigatoxin, which eventuates this syndrome, might induce TNF biosynthesis, and/or that TNF and shigatoxin might sensitize animals, each to the toxic effects of the other agent. Shigatoxin was found to sensitize mice to the lethal effect of LPS and to the lethal effect of TNF. On the other hand, pretreatment of animals with either TNF or LPS did not noticeably sensitize mice to the lethal effect of shigatoxin. Intraperitoneal injections of shigatoxin did not induce the production of detectable quantities of TNF in the plasma of mice. When shigatoxin was injected into transgenic mice bearing a chloramphenicol acetyltransferase (CAT) reporter gene that indicates TNF synthesis, CAT activity was induced within the kidney, but not in other tissues. We therefore conclude that shigatoxin acts to induce TNF synthesis within the kidney, and at the same time increases renal sensitivity to the toxic effects of TNF. While this mouse model does not reproduce the hemolytic uremic syndrome as it occurs in humans, it does suggest that local synthesis of TNF within the kidney may contribute to renal injury induced by shigatoxin. (J. Clin. Invest. 1993. 92:2110-2116.) Key words: hemolytic uremic syndrome - transgenic mouse • cytokine $\bullet$ kidney $\bullet$ exotoxin
\end{abstract}

\section{Introduction}

Hemolytic uremic syndrome, a leading cause of acute renal failure in childhood, is associated with infection by Shigella dysenteriae serotype I and by enterohemorrhagic Escherichia coli. The virulence of these organisms has been linked to the production of exotoxins ( shiga-like toxins [SLTs] ${ }^{1}$ ). There are two major SLTs: $E$. coli SLT-I is essentially identical to shigatoxin made by $S$. dysenteriae serotype I, while $E$. coli SLT-II is

Address correspondence to Dr. Bruce Beutler, Department of Internal Medicine, The University of Texas Southwestern Medical Center, 5323 Harry Hines Boulevard, Dallas, TX 75235-9050.

Received for publication 26 April 1993 and in revised form 25 June 1993.

1. Abbreviations used in this paper: CAT, chloramphenicol acetyltransferase; SLT, shiga-like toxin.

J. Clin. Invest.

(C) The American Society for Clinical Investigation, Inc.

$0021-9738 / 93 / 11 / 2110 / 07 \$ 2.00$

Volume 92, November 1993, 2110-2116 less closely related. Shigatoxins (also called verotoxins) have been shown to cause renal tubular damage in animal models (1). The pathologic changes produced do not precisely mimic those seen in human hemolytic uremic syndrome, perhaps because the shigatoxin receptor (Gb3) is not present on murine or lapine glomerular cells (2).

The mechanism of action of shigatoxin is clear. The toxin is a heterodimer, and acts as an inhibitor of protein synthesis, enzymatically modifying the translational machinery of the host cell (3). However, the precise contribution of shigatoxinmediated inhibition of protein synthesis to the development of hemolytic uremic syndrome remains mysterious. Inhibition of protein synthesis is not, by itself, entirely consistent with the pathologic changes that are observed. The fibrin deposition and coagulopathy that characterize hemolytic uremic syndrome are reminiscent of the changes that occur in systemic sepsis, in which cytokines, notably TNF, play a prominent role $(4,5)$.

Some recently published data suggest the possibility of cooperation between shigatoxin and TNF in producing the pathologic changes observed in hemolytic uremic syndrome (6-8). There may be either local or systemic induction of TNF synthesis by shigatoxin. Alternatively, TNF synthesis might be evoked in response to LPS, admitted from the gastrointestinal tract in the course of the hemorrhagic colitis that typically precedes hemolytic uremic syndrome. In either case, TNF might act in conjunction with shigatoxin to cause renal damage.

To study the events that take place after the entry of shigatoxins into the systemic circulation, we made use of a novel approach to the analysis of TNF biosynthesis and action. A chloramphenicol acetyltransferase (CAT) reporter of TNF production, present in transgenic animals, was used to determine the site(s) of TNF synthesis after shigatoxin (SLT-I) injection.

\section{Methods}

Mice. Animals used in these studies were of two types. $\mathrm{C} 3 \mathrm{H} / \mathrm{HeN}$ mice, obtained from Charles River Labs. (Wilmington, MA), were between 30 and $60 \mathrm{~d}$ of age. $\mathrm{C} 3 \mathrm{H} / \mathrm{HeJ}$ mice, obtained from The Jackson Laboratory (Bar Harbor, ME), were of the same age range. Transgenic mice, bearing the $\mathrm{CAT}_{\mathrm{TNF}}$ reporter construct (9) on a predominantly BALB/c background, were $30-75 \mathrm{~d}$ of age. The reporter construct contains the TNF promoter, 5'-untranslated region, and 3'-untranslated region, flanking a CAT coding sequence in the expected positions. It effectively mimicks the behavior of the TNF gene itself $(9,10)$.

Animals were maintained in the University of Texas Southwestern Medical Center Animal Resource Center, and were fed ad libitum. They were injected with shigatoxin, TNF, LPS, or saline as indicated by an intraperitoneal route. Animals were weighed daily thereafter, and either scored for survival, or killed for histological and enzymatic analy- 
Table I. Responses to Shigatoxin and LPS in C3H/HeN Mice

\begin{tabular}{ccccl}
\hline Shigatoxin & LPS & $\begin{array}{c}\text { Weight loss } \\
\text { at 4 d } \\
\text { (average) }\end{array}$ & $\begin{array}{c}\text { Survival } \\
\text { at 4 d }\end{array}$ & $\begin{array}{c}\text { Pathology evidence } \\
\text { of tubular injury }\end{array}$ \\
\hline$\mu g$ & $\mu g$ & $\%$ & $\%$ & \\
0.01 & - & $5-10$ & 100 & None \\
0.05 & - & $0-5$ & 100 & None \\
0.1 & - & 0 & 100 & None \\
0.3 & - & 15 & 100 & Mild \\
0.7 & - & 15 & 20 & Moderate \\
1.0 & - & 15 & 20 & Severe \\
2.0 & - & 15 & 20 & Severe \\
- & 20 & 5 & 100 & None \\
- & 100 & $5-10$ & 100 & None \\
- & 300 & 25 & 100 & None \\
- & 500 & 15 & 0 & Severe \\
- & 1,000 & 15 & 20 & Severe \\
& & & & \\
\hline
\end{tabular}

Each group contained five mice.

ses. The experiment shown in Fig. $6 C$ was performed three times. The other CAT assays in Figs. 6 and 7 were performed once. The experiments presented in Tables I and II were each performed on one occasion, using five animals per group.

Mouse TNF produced in E. coli was obtained from Genentech (S. San Francisco, CA). It had a specific activity of $2 \times 10^{7} \mathrm{U} / \mathrm{mg}$ protein, and contained $<1 \mathrm{ng}$ LPS $/ \mathrm{mg}$ protein.

Shigatoxin was prepared as previously described (11). It was assayed for LPS content by a colorimetric Limulus amoebacyte lysate test (12) in the laboratory of Dr. Eric Hansen (UT Southwestern Medical Center), and found to contain $16 \mathrm{ng} \mathrm{LPS} / \mu \mathrm{g}$ of shigatoxin protein.

LPS of E. coli strain 0155:B8 was obtained from Difco Laboratories (Detroit, MI) and dissolved in normal saline for use in these studies.

TNF bioassay was performed using L929 cells as the target for cytotoxicity, as previously described (13). The assay was sufficiently sensitive to detect TNF at a $10-\mathrm{pM}$ concentration.

Tissues from transgenic mice were homogenized in $0.25 \mathrm{M}$ Tris, $\mathrm{pH}$ 7.8 , and frozen and thawed once to prepare a lysate for CAT assay. The soluble fraction of the lysate was heated to $65^{\circ} \mathrm{C}$ and centrifuged before assay, as previously described (10). The thin-layer chromatography technique of Gorman et al. (14) was used to determine CAT activity. A CAT standard was obtained from 5 Prime- 3 Prime, Inc. (Boulder, $\mathrm{CO})$. Incubation time with the substrate was $4 \mathrm{~h}$.

Kidneys and colon were fixed in $10 \%$ neutral buffered formalin, processed in a standard manner, and stained with hematoxylin, eosin, and periodic acid-Schiff stains before microscopic examination.

\section{Results}

To assess the sensitivity to LPS and to shigatoxin of the population of mice used in these studies, dose-lethality curves were generated by injecting varying doses of each agent (Table I). Mice were weighed daily after injection of LPS or shigatoxin, and scored for survival as well. Animals that died were examined histopathologically, as were survivors, which were killed for this purpose $4 \mathrm{~d}$ after injection of LPS or shigatoxin.

From these initial studies, it was concluded that the mean lethal dose (MLD) of LPS was between 300 and $500 \mu \mathrm{g}$. The MLD of shigatoxin was between 0.3 and $0.7 \mu \mathrm{g}$. Each agent was capable of causing renal injury, which was apparent at a lightmicroscopic level. Morphologic changes were limited to the renal tubules. The glomeruli appeared no different from the controls, and microvascular thrombosis was absent. The colon was unremarkable in all animals (not shown). The pattern of tubular injury differed between animals treated with LPS and animals treated with shigatoxin. In the former, the distal (and to a lesser extent, the proximal) renal tubular cells focally displayed increased cytoplasmic eosinophila and nuclear pyknosis without karyorrhexis (Fig. 1). There was sloughing of some epithelial cells into the lumen. In shigatoxin-treated mice the distal tubules displayed nuclear vesiculation progressing to karyorrhexis, along with cytoplasmic vacuolation and fragmentation (Fig. 2). Nuclear pyknosis was also present to a lesser degree. Damage also involved the medullary collecting tubules of more severely affected animals. The proximal tubules showed only minimal focal nuclear pyknosis.

Pretreatment with shigatoxin sensitized mice to the lethal effect of LPS, but the converse (i.e., sensitization of mice to the

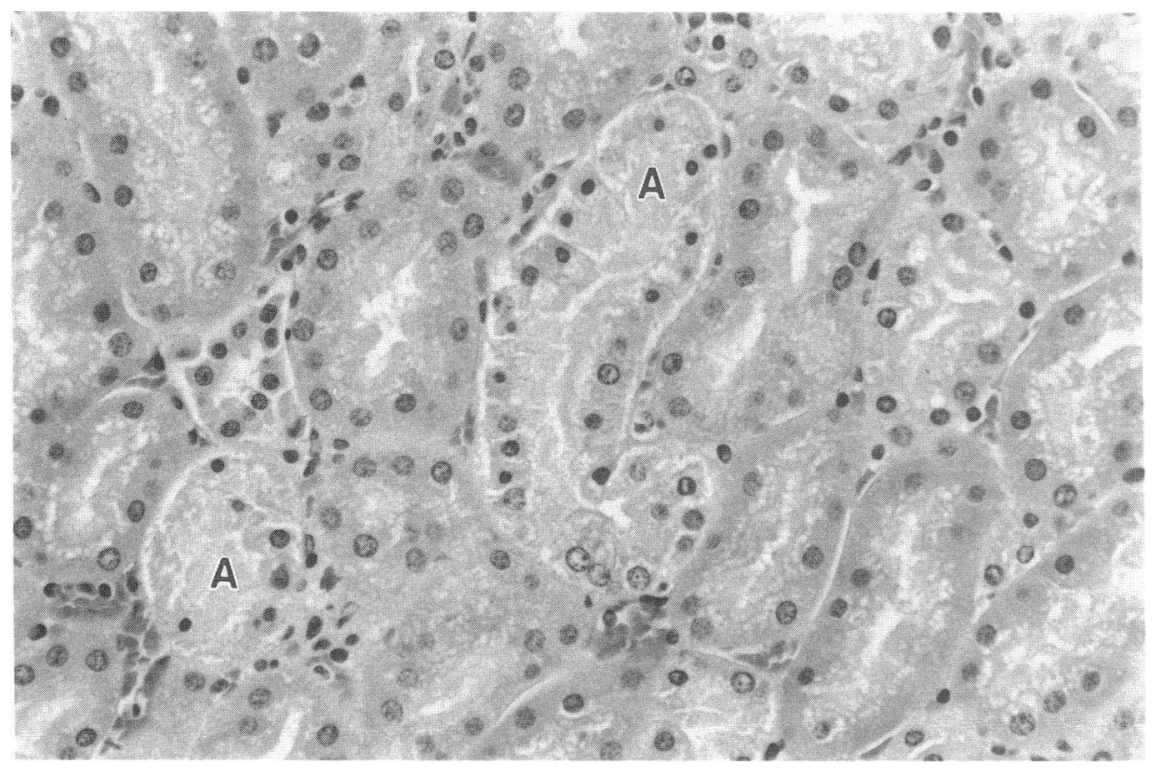

Figure 1. Histologic appearance of kidneys obtained from mice that were injected with LPS $(500 \mu \mathrm{g}) 3 \mathrm{~d}$ before death. The nuclei of some tubules are pyknotic $(A)$. The cytoplasm is granular and cells have separated from the basement membrane. Hematoxylin and eosin; $\times 400$. 


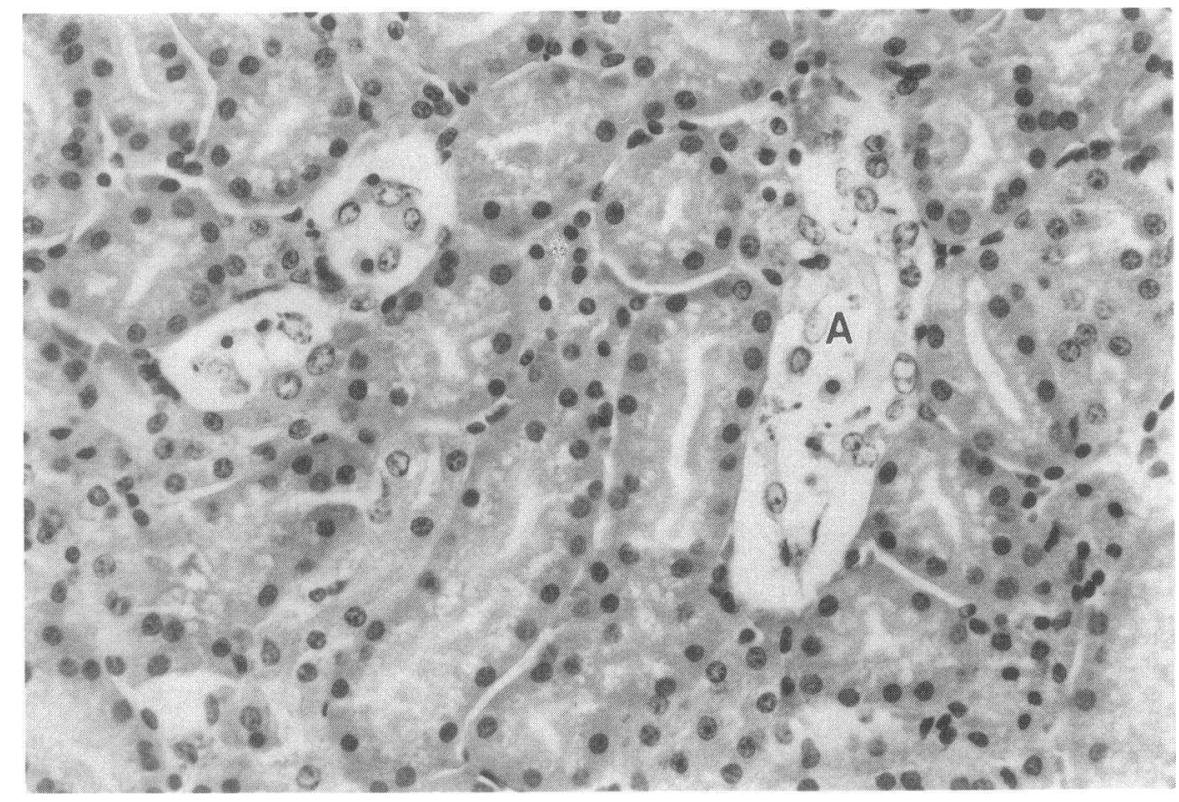

Figure 2. Histologic appearance of kidneys obtained from mice that received shigatoxin $(1.0 \mu \mathrm{g}) 5 \mathrm{~d}$ before death. Cells of distal tubules have sloughed from the basement membrane and many are vacuolated or have lysed $(A)$. While some nuclei are enlarged and vesicular, others are pyknotic or karyorrhectic. Hematoxylin and eosin; $\times 400$. lethal effect of shigatoxin by LPS) did not occur (Table II). The time interval required for sensitization by shigatoxin was investigated by challenging mice with LPS at various intervals after shigatoxin injection. Doses of LPS that were normally sublethal were sufficient to kill mice pretreated with shigatoxin, and the optimal sensitization interval was approximately $3 \mathrm{~d}$ (Table II). Histologic changes in the distal tubules were similar to, but more severe than, those observed after administration of shigatoxin alone (Fig. 3).

In view of the fact that TNF acts as a major mediator of LPS actions, we sought to determine whether shigatoxin would sensitize mice to the lethal effect of this cytokine, just as it appeared to sensitize to the effect of LPS. Pretreatment of mice with a normally sublethal dose of shigatoxin $(0.3 \mu \mathrm{g})$ followed $3 \mathrm{~d}$ later by injection of $20 \mu \mathrm{g}$ of TNF resulted in the death of all of the animals in the group (10/10). When the same TNF dose was injected into mice pretreated with normal saline, only three of nine animals died $(P<0.003)$. In the saline pretreatment groups histologic changes were limited to mild nuclear pyknosis of distal tubular epithelium in animals that died (Fig. 4). The histologic changes witnessed with shigatoxin pretreatment (Fig. 5) were similar to but less severe than those observed with shigatoxin and LPS.
When shigatoxin was administered to mice, no circulating TNF could be detected by biological assay of plasma samples, obtained at several intervals over a 3-d period of time (not shown). Considering the fact that TNF production might occur within specific tissues, and that the cytokine might exert its effect locally, shigatoxin was injected, either alone or in combination with LPS, into mice bearing a CAT reporter transgene that effectively indicates the biosynthesis of TNF in a tissuespecific fashion. Untreated mice expressed CAT activity only in the thymus, as previously reported (10). Similarly, mice treated with $1 \mu \mathrm{g}$ of LPS, a quantity far in excess of that present in the shigatoxin preparation, expressed CAT activity only in the thymus. By contrast, mice treated with shigatoxin consistently expressed the reporter both in the thymus and in the kidney. In the same experiment, coadministration of shigatoxin and LPS caused expression of CAT activity in the kidney at a level equal to or greater than that caused by shigatoxin alone; however, the significance of this finding is unclear, owing to variability of responses to shigatoxin among different mice (Fig. 6).

As an additional control designed to exclude the possibility that contaminating LPS, present in the shigatoxin preparation, was responsible for CAT biosynthesis in the kidney, heat-inac-

Table II. Effect of Administration of LPS to Mice at Varying Times Relative to Administration of Shigatoxin

\begin{tabular}{cccccc}
\hline Shigatoxin & LPS & $\begin{array}{c}\text { Time of LPS injection } \\
\text { before shigatoxin }\end{array}$ & $\begin{array}{c}\text { Weight loss at 4 d } \\
\text { (average) }\end{array}$ & $\begin{array}{c}\text { Survival } \\
\text { at 4 d }\end{array}$ & $\begin{array}{c}\text { Pathology evidence } \\
\text { of tubular injury }\end{array}$ \\
\hline$\mu g$ & $\mu g$ & $\%$ & $\%$ & 100 & None \\
0.3 & 20 & $-2 \mathrm{~d}$ & 20 & 100 & None \\
0.3 & 20 & $-1 \mathrm{~d}$ & 15 & 100 & None \\
0.3 & 20 & $-30 \mathrm{~min}$ & 15 & 20 & Moderate-severe \\
0.3 & 20 & $30 \mathrm{~min}$ & 15 & 20 & Moderate-severe \\
0.3 & 20 & $1 \mathrm{~d}$ & 15 & 20 & Moderate-severe \\
0.3 & 20 & $3 \mathrm{~d}$ & $0-5$ & 100 & None \\
0.3 & 20 & $5 \mathrm{~d}$ & & & \\
\hline
\end{tabular}

Each group contained five mice. 

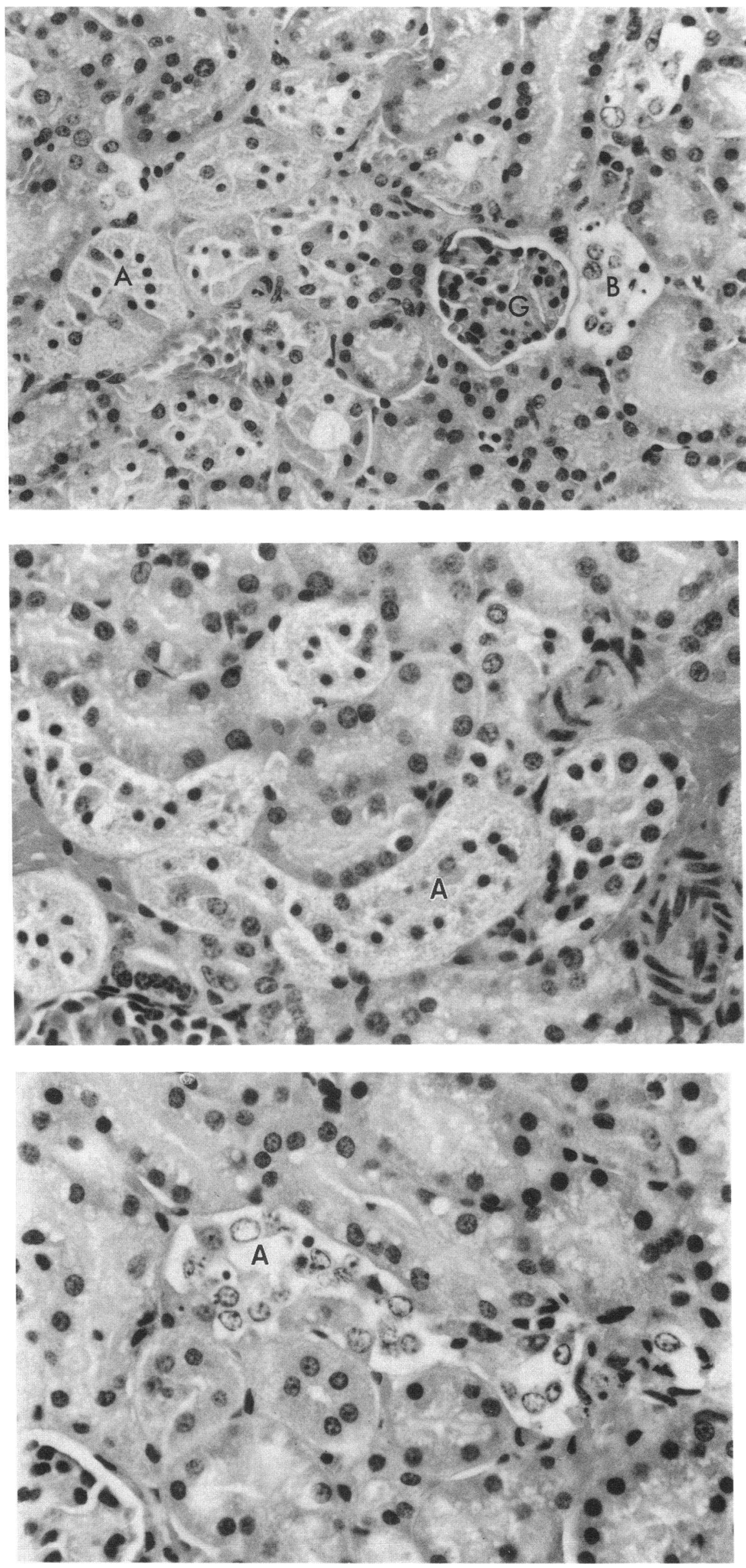

Figure 3. Histologic appearance of kidneys obtained from mice that received LPS ( 20 $\mu \mathrm{g})$ and shigatoxin $(0.3 \mu \mathrm{g})$ administered $1 \mathrm{~d}$ before death. Some of the tubular epithelial cells display granular cytoplasm with nuclear pyknosis $(A)$. Others display cytoplasmic vacuolation, nuclear vesiculation, and karyorrhexis $(B)$. Glomerulus $(G)$. Hematoxylin and eosin; $\times 400$.

Figure 4. Histologic appearance of kidneys obtained from mice that died after challenge with $20 \mu \mathrm{g}$ of recombinant TNF. Changes in the distal tubules consist of granular cytoplasmic degeneration and nuclear pyknosis $(A)$. The features were limited to the three animals that died; no changes were evident in kidneys of survivors (not shown). Hematoxylin and eosin, $\times 600$.
Figure 5. Histologic appearance of kidneys obtained from mice that received shigatoxin $(0.3$ $\mu \mathrm{g})$ and recombinant TNF (20 $\mu \mathrm{g})$ administered $1 \mathrm{~d}$ before death. Cytoplasmic condensation and/or vacuolation with cell sloughing are associated with nuclear vesiculation and karyorrhexis $(A)$. Hematoxylin and eosin, $\times 600$. 


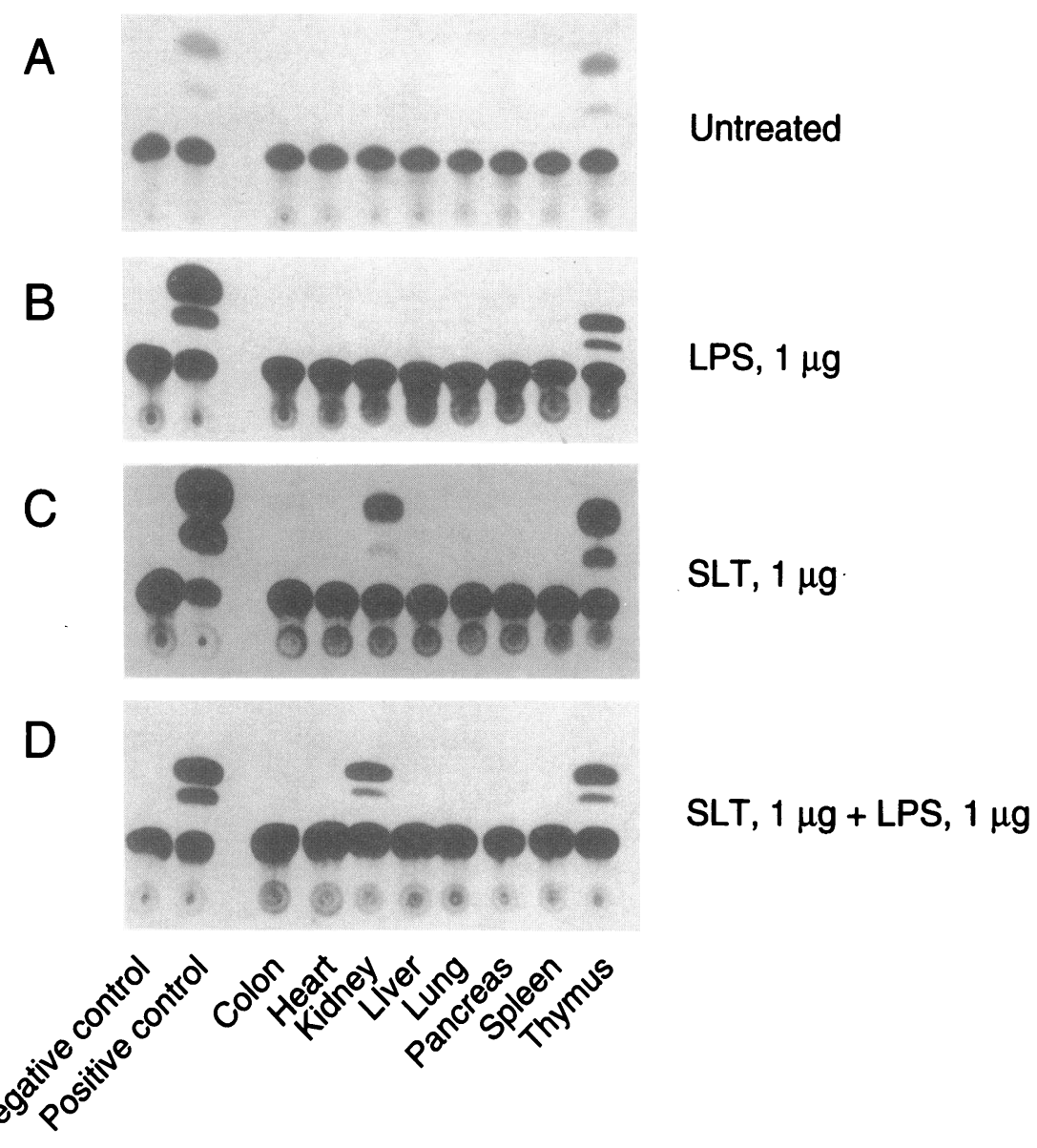

Figure 6. Induction of CAT activity in the tissues of transgenic mice by shigatoxin and/or LPS. ( $A$ ) Untreated animal (control). ( $B$ ) Administration of $1 \mu \mathrm{g}$ of LPS $1 \mathrm{~d}$ before death. (C) Administration of $1 \mu \mathrm{g}$ of shigatoxin $3 \mathrm{~d}$ before death. $(D)$ Administration of $1 \mu \mathrm{g}$ of shigatoxin $4 \mathrm{~d}$ before death, followed by $1 \mu \mathrm{g}$ of LPS $1 \mathrm{~d}$ before death.

tivated $\left(100^{\circ} \mathrm{C}\right.$ for $\left.1 \mathrm{~h}\right)$ preparations of shigatoxin were injected into transgenic mice. Heat-inactivated shigatoxin was incapable of inducing CAT expression within the kidney (Fig. 7), whereas nondenatured shigatoxin induced renal CAT synthesis as it had done previously. When the timing of CAT activity was assessed with respect to shigatoxin administration, renal CAT activity in transgenic mice was noted at $3 \mathrm{~d}$ postshigatoxin but not at $2 \mathrm{~d}, 1 \mathrm{~d}$, or $6 \mathrm{~h}$ (Fig. 8 ). This result is consistent with a biological effect of a toxin other then LPS, which induces reporter gene expression far more quickly (15), and in a different set of tissues. Moreover, shigatoxin preparations administered to $\mathrm{C} 3 \mathrm{H} / \mathrm{HeJ}$ mice at a dose of $0.3 \mu \mathrm{g}$ caused renal injury identical to that observed in $\mathrm{C} 3 \mathrm{H} / \mathrm{HeN}$ animals (data not shown).

\section{Discussion}

Previous work carried out with the reporter transgene used in the present study has revealed that TNF is constitutively synthesized within the thymus (10), and that numerous tissues produce TNF in response to LPS injection (15). The notion that other inducers, including bacterial exotoxins such as shigatoxin, might cause entirely different patterns of TNF biosynthesis within host tissues is quite novel. It may now be considered that TNF might contribute to the pathogenesis of many different toxic syndromes, and may influence the course of diseases, based upon its production and action at different sites in the body, over specific intervals of time. It may be imagined that shigatoxin exerts a specific effect on renal tissue by virtue of the distribution of its receptor, and perhaps as a result of postreceptor constraints as well.

We have demonstrated that shigatoxin is able to induce the biosynthesis of TNF within the kidney, and that TNF contributes to the development of renal injury that ensues after shigatoxin injection. This conclusion is based on the following observations. (a) Shigatoxin strongly potentiates the nephrotoxic effect of LPS and of TNF. However, these agents do not potentiate the nephrotoxic effect of shigatoxin, and; $(b)$ a reporter transgene indicates that shigatoxin is capable of inducing TNF synthesis within the kidney, but no other tissue.

Attempts to identify the biosynthesis of TNF itself in renal tissue through bioassay of organ culture supernatant were unsuccessful. We have previously noted that it is not possible to detect TNF synthesis elicited by LPS in the kidney (15), apparently because tubular cells secrete enzymes that degrade TNF or act as a "sink" for TNF, even when exogenous protein is added to the organ culture system. Therefore, we considered reporter gene activation to be indicative of TNF synthesis even though direct assay of renal TNF was not possible.

The cells that produce TNF within the kidney remain to be identified. It is possible that they are mononuclear cells that invade the kidney in response to the injury initiated by shigatoxin. Alternatively, they may represent components of the kidney itself, either within the glomeruli or within the tubules. Notably, it has been shown that glomerular cells are capable of producing TNF in response to LPS in vitro (15). To date, 
A
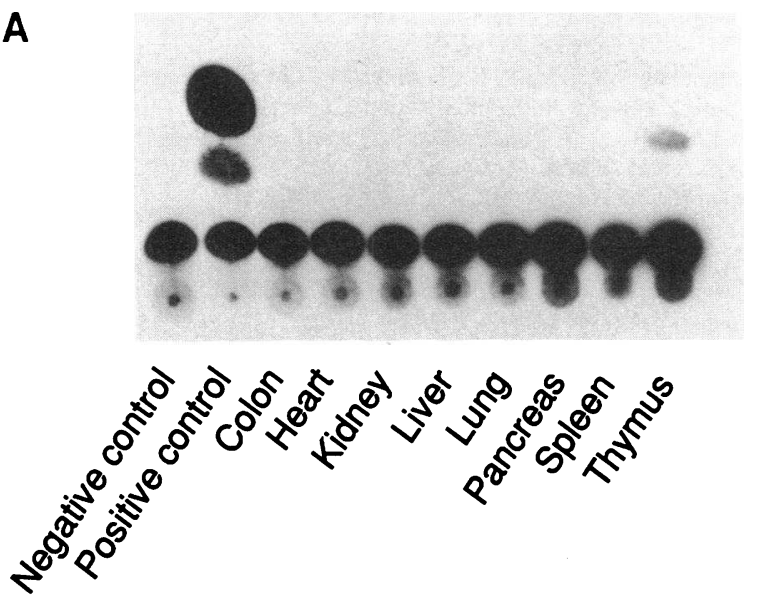

B
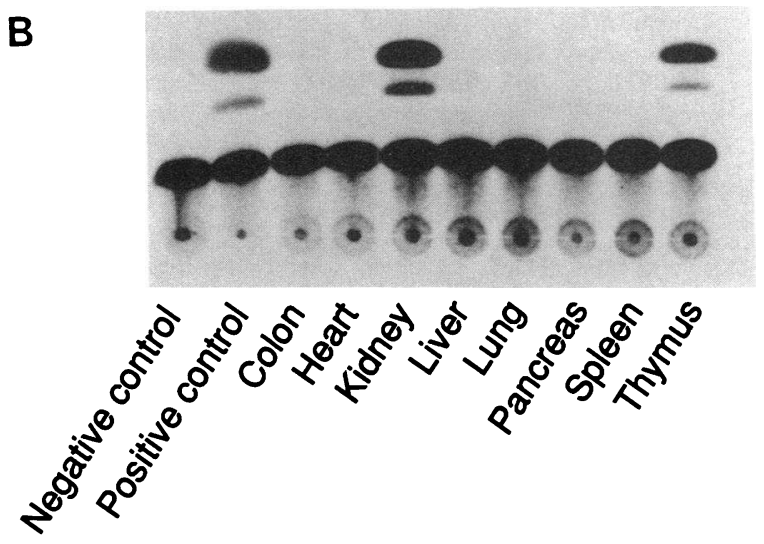

Figure 7. (A) Assay of CAT activity in tissues obtained from a $\mathrm{CAT}_{\mathrm{TNF}}$ transgenic mouse that received heat-inactivated shigatoxin $(1 \mu \mathrm{g}) 5 \mathrm{~d}$ before death. $(B)$ Assay of CAT activity in tissues obtained from a $\mathrm{CAT}_{\mathrm{TNF}}$ transgenic mouse that received active shigatoxin (1 $\mu \mathrm{g}) 5 \mathrm{~d}$ before death.

immunocytochemical analysis has been inadequate to determine the cellular source of CAT activity, perhaps because the CAT assay far exceeds immunocytochemistry in terms of sensitivity (B. Beutler, unpublished observation).

Why does shigatoxin potentiate the lethal and nephrotoxic effect of LPS (and of TNF itself)? Presumably, when LPS (or TNF itself) is injected systemically, a fraction of the TNF generated (or directly administered) reaches the kidney, and can contribute to the pathogenic effect wrought by TNF that has been produced locally. This finding would suggest that while shigatoxin is capable of inducing TNF within the kidney, it ordinarily fails to elicit production of quantities that are capable of causing maximum damage.

LPS may potentiate shigatoxin-induced release of TNF within the kidney. This possibility is suggested by the behavior of the reporter transgene, which was more highly expressed in the presence of LPS and shigatoxin than in the presence of shigatoxin alone. On the one hand, it is possible that the observation relates only to the experimental situation, insofar as shigatoxin, whatever its signaling mechanism, may "prime" cells for an enhanced response to LPS challenge. Indeed, it is clear that shigatoxin may cause a nephrotoxic effect in the absence of any LPS effect, since it does so in $\mathrm{C} 3 \mathrm{H} / \mathrm{HeJ}$ mice. However, it would seem likely that the observation has relevance in hemolytic uremic syndrome itself. In authentic hemolytic uremic syndrome, it is likely that hemorrhagic colitis is associated with the influx of bacterial endotoxin from the intestinal tract, and that both shigatoxin and LPS are present within the circulation during the course of the disease. Thus, insofar as humans are exquisitely sensitive to LPS, the conjoint presence of shigatoxin and LPS may cause exaggerated TNF production, and renal injury.

Recently, van der Kar et al. (16) reported that TNF treatment of human vascular endothelial cells led to enhanced biosynthesis of the shigatoxin receptor, thereby sensitizing cells to the cytotoxic action of shigatoxin. This observation would also suggest an interaction between LPS, TNF, and shigatoxin, although it is somewhat at variance with the finding that, in mice, shigatoxin could sensitize to the lethal effect of LPS or TNF, but these latter two agents could not sensitize to the lethal effect of shigatoxin. We are inclined to consider that the apparent discrepancy may be explained by a species difference, or by differences between the two experimental systems (e.g., the in vitro vs. in vivo administration of toxin). Overall, we favor the model depicted in Fig. 9 as an illustration of the roles played by LPS, shigatoxin, and TNF in the hemolytic uremic syndrome.

The participatory role of TNF in hemolytic uremic syndrome, as modeled by mice treated with shigatoxin, would immediately suggest therapeutic possibilities, in that antibodies directed against TNF, or soluble TNF receptors (17), might mitigate the effects of shigatoxin in human patients with hemolytic uremic syndrome. Since the inducing agent may persist for a period of several days, it is reasonable to consider that TNF induction may be a chronic process in hemolytic uremic syndrome; perhaps more so than in sepsis. Thus, the period of time during which effective intervention may be possible could be relatively long.

The value of the transgenic model that we have devised for the identification of TNF biosynthesis in vivo is well illustrated

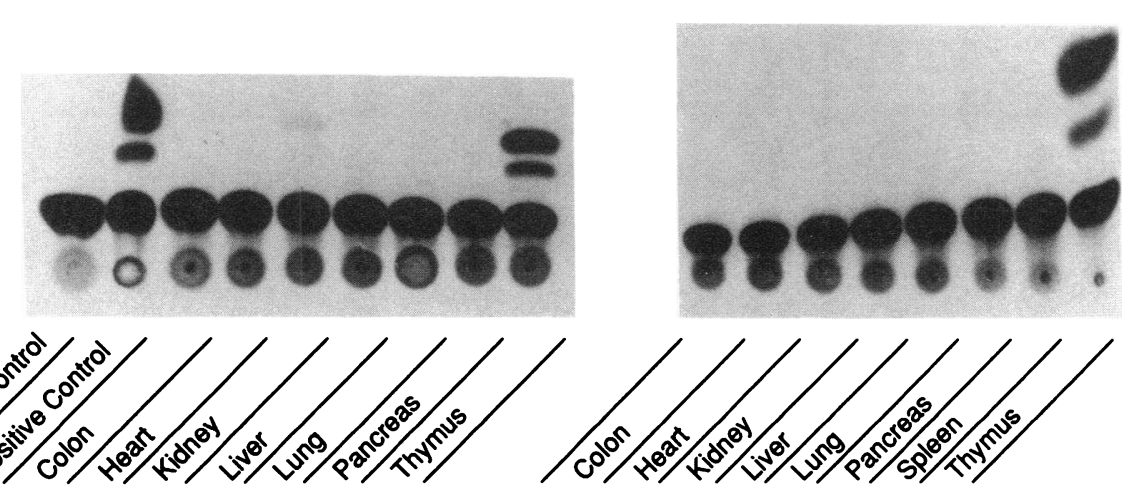

Figure 8. Assay of CAT activity in tissues obtained from CAT $_{\text {TNF }}$ transgenic mice that received $1 \mu \mathrm{g}$ of shigatoxin, 3 or $2 \mathrm{~d}$ before death. Earlier time points ( $1 \mathrm{~d}$ and $6 \mathrm{~h}$ ) were negative for renal CAT activity, and are not shown. 


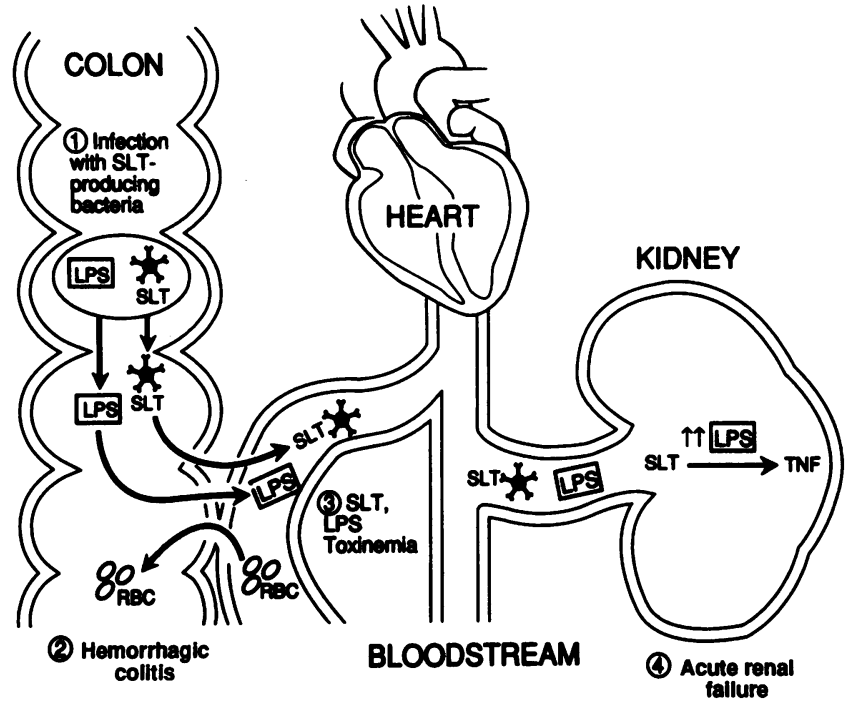

Figure 9. Schematic illustration of the roles played by LPS, shigatoxin, and TNF in the pathogenesis of HUS.

by these studies. Presumably, these animals will be used in the identification of many other disease states in which TNF is a central participant.

\section{Acknowledgments}

This work was supported by grants from the National Institutes of Health (5-P01 DK-42582 and 2-P01 HD-13021015), and by a grant from the Tobacco Research Council (59636).

\section{References}

1. Barrett, T. J., M. E. Potter, and I. K. Wachsmuth. 1989. Continuous peritoneal infusion of Shiga-like toxin II (SLT II) as a model for SLT II-induced diseases. J. Infect. Dis. 159:774-777.
2. Karmali, M. A. 1992. Infection by verocytotoxin-producing Escherichia coli. Clin. Microbiol. Rev. 2:16-33.

3. Donohue-Rolfe, A., D. W. K. Acheson, and G. T. Keusch. 1991. Shiga toxin: purification, structure, and function. Rev. Infect. Dis. 13(4):S293-S297.

4. Beutler, B., I. W. Milsark, and A. Cerami. 1985. Passive immunization against cachectin/tumor necrosis factor (TNF) protects mice from the lethal effect of endotoxin. Science (Wash. DC). 229:869-871.

5. Tracey, K. J., B. Beutler, S. F. Lowry, J. Merryweather, S. Wolpe, I. W. Milsark, R. J. Hariri, T. J. I. Fahey, A. Zentella, J. D. Albert, G. T. Shires, and A. Cerami. 1986. Shock and tissue injury induced by recombinant human cachectin. Science (Wash. DC). 234:470-474.

6. Barrett, T. J., M. E. Potter, and I. K. Wachsmuth. 1989. Bacterial endotoxin both enhances and inhibits the toxicity of shiga-like toxin II in rabbits and mice. Infect. Immun. 57:3434-3437.

7. Barrett, T. J., M. E. Potter, and N. A. Strockbine. 1990. Evidence for participation of the macrophage in Shigalike toxin II-induced lethality in mice. Microb. Pathog. 9:95-103.

8. Tesh, V. L., J. E. Samuel, L. P. Perera, J. B. Sharefkin, and A. D. O'Brien. 1991. Evaluation of the role of Shiga and Shiga-like toxins in mediating direct damage to human vascular endothelial cells. J. Infect. Dis. 164:344-352.

9. Beutler, B., and T. Brown. 1991. A CAT reporter construct allows ultrasensitive estimation of TNF synthesis, and suggests that the TNF gene has been silenced in non-macrophage cell lines. J. Clin. Invest. 87:1336-1344.

10. Giroir, B. P., T. Brown, and B. Beutler. 1992. Constitutive synthesis of tumor necrosis factor in the thymus. Proc. Natl. Acad. Sci. USA. 89:4864-4868.

11. Prado, D., T. G. Cleary, L. K. Pickeeing, C. D. Erickson, A. V. Batlett, H. L. DuPont, and P. C. Johnson. 1986. The relation between production of cytotoxin and clinical features in shigellosis. J. Infect. Dis. 154:149-155.

12. Levin, J., T. E. Poore, N. P. Zauber, and R. S. Oser. 1970. Detection of endotoxin in the blood of patients with sepsis due to gram-negative bacteria. $N$. Engl. J. Med. 283:1313-1316.

13. Cseh, K., and B. Beutler. 1989. Alternative cleavage of the cachectin/TNF propeptide results in a larger, inactive form of secreted protein. J. Biol. Chem. 264:16256-16260.

14. Gorman, C. M., L. F. Moffat, and B. H. Howard. 1982. Recombinant genomes which express chloramphenicol acetyltransferase in mammalian cells. Mol. Cell. Biol. 2:1044-1051.

15. Giroir, B. P., J. H. Johnson, T. Brown, G. L. Allen, and B. Beutler. 1992. The tissue distribution of TNF biosynthesis during endotoxemia. J. Clin. Invest. 90:693-698.

16. van de Kar, N. C. A. J., L. A. H. Monnens, M. A. Karmali, and V. W. M. Van Hinsbergh. 1992. Tumor necrosis factor and interleukin-1 induce expression of the verocytotoxin receptor globotriaosylceramide on human endothelial cells: implications for the pathogenesis of the hemolytic uremic syndrome. Blood. 80:2755-2764.

17. Peppel, K., D. Crawford, and B. Beutler. 1991. A tumor necrosis factor (TNF) receptor-IgG heavy chain chimeric protein as a bivalent antagonist of TNF activity. J. Exp. Med. 174:1483-1489. 